\title{
No increase in the prevalence of COPD in
}

\section{two decades}

\author{
T.M. Vasankari*, O. Impivaara\#, M. Heliövaara ", S. Heistaro+, K. Liippo*, P. Puukka ${ }^{\#}$, \\ S. Saarelainen ${ }^{\S}$, M. Kanervisto ${ }^{\dagger}$ and P. Jousilahti ${ }^{+}$
}

ABSTRACT: Relevant information on the prevalence of chronic obstructive pulmonary disease (COPD) and its trends is scarce. In the present study, we compare the prevalence rates and potential determinants of COPD in two national population samples that were surveyed 20 yrs apart.

In 1978-1980, a sample of 8,000 people was surveyed; subjects were representative of the Finnish population and were aged $\geqslant 30 \mathrm{yrs}$. Among those aged $30-74 \mathrm{yrs}$, acceptable spirometry was obtained from 6,364 (87\%) subjects. In a similar survey conducted in 2000-2001, comparable spirometry was obtained from 5,495 (80\%) participants. Airway obstruction was defined as forced expiratory volume in $1 \mathrm{~s}\left(\mathrm{FEV} \mathrm{V}_{1}\right)$ /forced vital capacity below the lower limit of normal and staged for severity on the basis of $\mathrm{FEV}_{1} \%$ predicted.

The age-adjusted prevalence rates of obstruction (stages I-IV) were rather similar in both surveys in males (4.7 versus $4.3 \% ; p=0.25$ ), but were almost significantly higher in females in the later survey (2.2 versus $3.1 \% ; p=0.06)$. The rates of COPD stage II or higher were $3.9 \%$ in $1978-1980$, and $3.6 \%$ in 2000-2001 $(p=0.36)$ for males, and 1.4 and $1.5 \%(p=0.93)$, respectively, for females.

In conclusion, no significant difference was found in the prevalence of COPD stages II-IV between similar population based surveys performed $\mathbf{2 0}$ yrs apart. Since COPD is mostly mild or moderate there is a strong case for early prevention.

KEYWORDS: Bronchial obstruction, epidemiology, lower limit of normal, spirometry, tobacco smoking

hronic obstructive pulmonary disease (COPD) is one of the leading causes of morbidity, disability and death worldwide [1-3]. The prevalence of COPD depends on the distributions of age and sex, and the levels of risk factors, such as tobacco smoking in the population [3, 4]. Spirometric criteria for the diagnosis and staging of COPD were issued by the Global Initiative for Chronic Obstructive Lung Disease (GOLD) in 2006; they define airway obstruction as an observed fixed ratio of forced expiratory volume in $1 \mathrm{~s}$ (FEV1)/forced vital capacity (FVC) of $<70 \%$, classifying this abnormality on the basis of FEV1 \% predicted [5]. However, compared with the use of the lower limit of normal (LLN) for the FEV1/FVC ratio, this fixed cut-off approach has recently been shown to overestimate the prevalence of COPD in older adults and to underestimate it in younger people [6-10].

Thus, the reported prevalence rates of COPD vary widely depending on the populations studied and the definitions of COPD used. Using the GOLD (fixed ratio) criteria, the overall prevalence of COPD (GOLD stage II or higher) was $10.1 \%$ among subjects aged $\geqslant 40 \mathrm{yrs}$ in a large population-based study covering a variety of geographical sites around the world [11]. Applying the LLN criterion to define obstruction, the corresponding prevalence of COPD in the same material was $8.3 \%$ (9.1\% for males and $7.9 \%$ for females), ranging $5.0-16.3 \%$ across the study sites [10]. Regardless of the rules used to define COPD, the socioeconomic burden of this disease is anticipated to increase substantially worldwide along with continued tobacco smoking and the growing number of elderly people in society [1, 3]. However, very little is known about the trends in the prevalence of COPD.

The first nationally representative study on the prevalence of airway obstruction in Finland was based on the Mini Finland Health Survey carried out in 1978-1980 [12]. In that study, nonspecific airway obstruction was found in $11 \%$ of males
AFFILIATIONS

*Dept of Respiratory Medicine, Turku University Hospital,

\#Population Studies Unit, National Institute for Health and Welfare, Turku,

'Living Conditions, Health and Wellbeing Unit,

+International Affairs Unit, National Institute for Health and Welfare, Helsinki,

${ }^{\S}$ Respiratory Medicine Outpatient Unit, Tampere University Hospital, and

${ }^{f}$ Dept of Nursing Science, University of Tampere, Tampere, Finland.

CORRESPONDENCE

T.M. Vasankari Dept of Respiratory Medicine

Turku University Hospital

PL 52

FI 20521

Turku

Finland

E-mail: tuula.vasankari@utu.fi

Received:

Nov 102009

Accepted after revision:

July 122010

First published online:

Aug 062010 
and $5 \%$ of females [13]. The Health 2000 Survey designed to be comparable with the Mini Finland Health Survey was conducted in 2000-2001 [14, 15]. We calculated the prevalence rates of various stages of COPD in 30-74 yr-old Finns derived from these nationally representative surveys, which were carried out 20 yrs apart, and explored whether the prevalence rates and determinants of COPD had undergone any appreciable changes between the surveys. In these calculations we defined airway obstruction according to the FEV1/FVC $<$ LLN criteria [16] and classified this abnormality into the four stages of severity on the basis of FEV1 \% pred as defined by GOLD [5].

\section{STUDY POPULATIONS AND METHODS}

In 1978-1980, a sample of 8,000 subjects $(3,637$ males and 4,363 females) representative of the Finnish population aged $\geqslant 30$ yrs, was drawn from the population register and invited to a comprehensive health survey (Mini Finland Health Survey); 7,217 subjects participated [12]. Information on lifestyle, health status and chronic illness diagnosed by a physician was elicited by means of questionnaires, as well interviews performed by specially trained nurses. The methods also included lung function tests. Acceptable spirometry was obtained from 3,015 males and 3,349 females ( $87 \%$ of those aged 30-74 yrs in the sample).

The Health 2000 Survey (performed in 2000-2001) was similarly based on a representative sample of 8,028 subjects $(3,637$ males and 4,391 females) aged $\geqslant 30$ yrs [14, 15]. Wherever appropriate, this survey was designed to be comparable with the former survey. The participants were asked mostly the same questions about socioeconomic background, lifestyle and illness as had been asked in the previous survey. In total, 6,354 subjects participated, and acceptable spirometry was obtained from 2,572 males and 2,923 females ( $80 \%$ of the sample).

In both surveys, smoking history was obtained through a standard interview and classified into three categories: neversmokers, former smokers (those who had quit smoking $\geqslant 1$ month prior to the survey) and current smokers (those who had smoked daily at least one cigarette, cigar or pipe for $\geqslant 1 \mathrm{yr}$ preceding the survey). Educational level was categorised into three groups: basic, secondary or higher. Leisure physical activity was classified into three groups: low (little physical exercise), moderate (exercise in connection with some hobbies or irregularly) or high (regular exercise).

Vitalograph bellow spirometers (Vitalograph Ltd., Buckingham, UK) were used in both surveys. The measurements were made by specially trained laboratory technicians following standard guidelines and instructions. The technicians demonstrated the test procedure to all subjects separately. When the subject had learned the technique and rehearsed it once or twice, the aim was to produce at least two curves that were as consistent as possible. For FEV1 and FVC, the technician instructed the subjects to fill their lungs with air and then to exhale as forcefully and completely as possible, urging them towards the end of the test. Failed efforts and those with questionable performance due to fatigue, or otherwise poor cooperation, were excluded from the analysis. The quotient FEV1/FVC was calculated using the highest readings of FEV1 and FVC from technically acceptable efforts recorded in BTPS (body temperature and pressure, saturated with water vapor). FEV1/FVC $<$ LLN was considered to indicate airway obstruction [16]. The individual results were computed on the basis of the SAPALDIA reference values [17] for corresponding age, sex and height. Airway obstruction was further classified into four stages of severity according to the GOLD criteria [5]. An

\section{TABLE 1 Subject characteristics in the two study populations}

\begin{tabular}{|c|c|c|}
\hline & $\begin{array}{l}\text { Mini Finland Health } \\
\text { Survey }(1978-1980)\end{array}$ & $\begin{array}{l}\text { Health } 2000 \text { Survey } \\
\qquad(2000-2001)\end{array}$ \\
\hline Males $n$ & 3015 & 2572 \\
\hline Age yrs & $47.3 \pm 0.25$ & $49.2 \pm 0.25$ \\
\hline Height cm & $173.5 \pm 0.12$ & $176.6 \pm 0.15$ \\
\hline Weight kg & $77.7 \pm 0.23$ & $84.5 \pm 0.30$ \\
\hline $\mathrm{BMI}$ & $25.8 \pm 0.08$ & $27.1 \pm 0.09$ \\
\hline \multicolumn{3}{|l|}{ Level of education } \\
\hline Higher & 13.3 & 25.4 \\
\hline Secondary & 22.5 & 39.5 \\
\hline Basic & 64.2 & 35.1 \\
\hline \multicolumn{3}{|c|}{ Physical activity at leisure } \\
\hline High & 19.3 & 22.2 \\
\hline Moderate & 50.5 & 51.7 \\
\hline Low & 30.2 & 26.1 \\
\hline \multicolumn{3}{|l|}{ Smoking status } \\
\hline Never & 29.5 & 36.4 \\
\hline Former & 33.0 & 29.3 \\
\hline Current & 37.5 & 34.3 \\
\hline $\begin{array}{l}\text { Previously diagnosed } \\
\text { asthma }\end{array}$ & 1.4 & 2.8 \\
\hline $\begin{array}{l}\text { Previously diagnosed } \\
\text { pulmonary TB }\end{array}$ & 1.0 & None reported \\
\hline Females $\mathbf{n}$ & 3349 & 2923 \\
\hline Age yrs & $49.5 \pm 0.31$ & $50.2 \pm 0.22$ \\
\hline Height $\mathrm{cm}$ & $160.1 \pm 0.12$ & $162.9 \pm 0.14$ \\
\hline Weight kg & $66.1 \pm 0.20$ & $70.8 \pm 0.25$ \\
\hline BMI & $25.8 \pm 0.08$ & $26.7 \pm 0.09$ \\
\hline \multicolumn{3}{|l|}{ Level of education } \\
\hline Higher & 12.6 & 35.2 \\
\hline Secondary & 23.1 & 29.1 \\
\hline Basic & 64.4 & 35.7 \\
\hline \multicolumn{3}{|c|}{ Physical activity at leisure } \\
\hline High & 14.7 & 15.7 \\
\hline Moderate & 49.2 & 60.5 \\
\hline Low & 36.1 & 23.8 \\
\hline \multicolumn{3}{|l|}{ Smoking status } \\
\hline Never & 74.7 & 61.6 \\
\hline Former & 10.9 & 14.7 \\
\hline Current & 14.3 & 23.7 \\
\hline $\begin{array}{l}\text { Previously diagnosed } \\
\text { asthma }\end{array}$ & 2.2 & 5.2 \\
\hline $\begin{array}{l}\text { Previously diagnosed } \\
\text { pulmonary TB }\end{array}$ & 0.4 & None reported \\
\hline
\end{tabular}




\begin{tabular}{|c|c|c|c|}
\hline $\begin{array}{l}\text { Spirometric } \\
\text { bronchodila }\end{array}$ & $\begin{array}{l}\text { asurements ( } \\
\text { in the two st }\end{array}$ & $\begin{array}{l}\text { vithout } \\
\text { urveys }\end{array}$ & \\
\hline & $\begin{array}{l}\text { Mini-Finland } \\
\text { Health Survey }\end{array}$ & $\begin{array}{l}\text { Health } 2000 \\
\text { Survey }\end{array}$ & p-value \\
\hline Males $\mathbf{n}$ & 3015 & 2572 & \\
\hline FEV 1 L & & & 0.004 \\
\hline Mean \pm SEM & $3.96 \pm 0.025$ & $3.79 \pm 0.019$ & \\
\hline Range & $0.70-6.60$ & $0.50-6.50$ & \\
\hline Age-adjusted mean \pm SEM & $3.89 v 0.021$ & $3.79 \pm 0.015$ & \\
\hline FEV $1 \%$ pred & & & $<0.001$ \\
\hline Mean \pm SEM & $100.95 \pm 0.54$ & $94.88 \pm 0.36$ & \\
\hline Range & $19.71-158.84$ & $15.00-150.27$ & \\
\hline Age-adjusted mean \pm SEM & $100.1 \pm 0.52$ & $94.69 \pm 0.35$ & \\
\hline FVC L & & & 0.22 \\
\hline Mean \pm SEM & $4.93 \pm 0.031$ & $4.79 \pm 0.023$ & \\
\hline Range & $1.10-8.20$ & $0.80-8.00$ & \\
\hline Age-adjusted mean \pm SEM & $4.86 \pm 0.028$ & $4.79 \pm 0.018$ & \\
\hline FVC \% pred & & & $<0.001$ \\
\hline Mean \pm SEM & $98.17 \pm 0.55$ & $92.58 \pm 0.32$ & \\
\hline Range & 28.92-147.39 & $19.81-135.81$ & \\
\hline Age-adjusted mean \pm SEM & $97.55 \pm 0.53$ & $92.59 \pm 0.30$ & \\
\hline $\mathrm{FEV}_{1} / \mathrm{FVC}$ & & & 0.042 \\
\hline Mean \pm SEM & $79.79 \pm 0.21$ & $78.87 \pm 0.14$ & \\
\hline Range & $37.50-97.80$ & $23.10-96.90$ & \\
\hline Age-adjusted mean \pm SEM & $79.38 \pm 0.19$ & $78.77 \pm 0.14$ & \\
\hline Females $\mathbf{n}$ & 3349 & 2923 & \\
\hline FEV 1 L & & & $<0.001$ \\
\hline Mean \pm SEM & $2.90 \pm 0.016$ & $2.79 \pm 0.012$ & \\
\hline Range & $0.60-5.00$ & $0.50-4.90$ & \\
\hline Age-adjusted mean \pm SEM & $2.92 \pm 0.011$ & $2.83 \pm 0.010$ & \\
\hline FEV1 \% pred & & & $<0.001$ \\
\hline Mean \pm SEM & $105.28 \pm 0.39$ & $98.94 \pm 0.31$ & \\
\hline Range & $31.39-167.36$ & $28.44-149.08$ & \\
\hline Age-adjusted mean \pm SEM & $105.44 \pm 0.38$ & $99.09 \pm 0.30$ & \\
\hline FVC L & & & 0.079 \\
\hline Mean \pm SEM & $3.53 \pm 0.017$ & $3.47 \pm 0.015$ & \\
\hline Range & $1.20-6.20$ & $0.90-6.10$ & \\
\hline Age-adjusted mean \pm SEM & $3.55 \pm 0.014$ & $3.50 \pm 0.013$ & \\
\hline FVC \% pred & & & $<0.001$ \\
\hline Mean \pm SEM & $101.08 \pm 0.38$ & $95.87 \pm 0.31$ & \\
\hline Range & $42.92-148.36$ & $36.32-143.08$ & \\
\hline Age-adjusted mean \pm SEM & $101.27 \pm 0.37$ & $96.17 \pm 0.30$ & \\
\hline $\mathrm{FEV}_{1 / F V C}$ & & & $<0.001$ \\
\hline Mean \pm SEM & $81.66 \pm 0.14$ & $80.40 \pm 0.14$ & \\
\hline Range & $45.80-98.00$ & $46.40-97.50$ & \\
\hline Age-adjusted mean \pm SEM & $81.80 \pm 0.11$ & $80.55 \pm 0.13$ & \\
\hline
\end{tabular}

FEV1: forced expiratory volume in $1 \mathrm{~s}$; \% pred: \% predicted; FVC: forced vital capacity.

abnormal nonspecific pattern of pulmonary function test (FEV1/FVC $\geqslant L L N$ and FVC $<80 \%$ pred) was calculated to check whether a possible change in the prevalence of obstruction might be interconnected with a change in the prevalence of such a nonspecific pattern [18].

Subjects were considered asthmatic if they reported that they had been diagnosed with asthma by a physician, that they
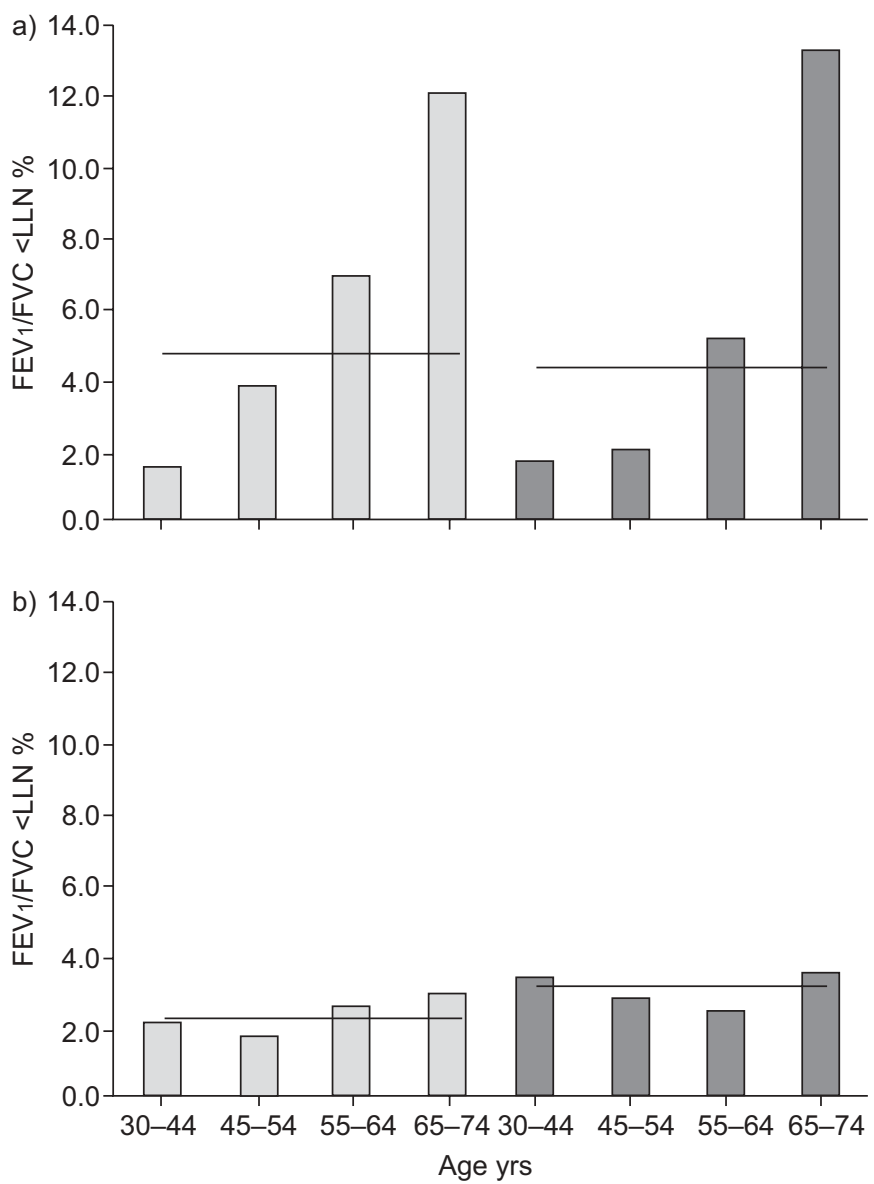

FIGURE 1. Prevalence of bronchial obstruction defined as forced expiratory volume in $1 \mathrm{~s}(\mathrm{FEV} 1) /$ forced vital capacity (FVC) below the lower limit of normal $(<L L N)$ in a) males and b) females in the Mini Finland Health Survey (performed in 1978-1980; ${ }^{-}$) and in the Health 2000 Survey (performed in 2000-2001; - )

were currently seeing a physician control and had received medication for asthma. Participants were also asked whether pulmonary tuberculosis had ever been diagnosed by a physician.

The Health 2000 Survey was approved by the Ethical Committee for epidemiology and public health in the hospital district of Helsinki and Uusimaa, Finland. All participants gave their written informed consent. The Mini Finland Health Survey was carried out long before the current legislation involving medical research in human subjects became effective. The subjects were informed about the use of the collected data for research purposes, and consented to participate on a voluntary basis in compliance with the principles of the World Medical Association (WMA) Declaration of Helsinki.

The data were analysed using SAS 9.1 (SAS Institute, Cary, NC, USA) survey procedures and SUDAAN 9 software (Research Triangle Institute, Raleigh, NC, USA). SUDAAN is specifically designed to analyse cluster-correlated data in complex sample surveys [19]. Descriptive statistics were calculated using weighting adjustment to allow for the survey design, including clustering and stratification of the sample, and also for non-participation. Because of these weighting 
adjustments, SEM, instead of the conventional SD, was calculated to indicate variability around the mean values of continuous variables. The prevalence rates of airway obstruction and various stages of COPD in the two surveys were adjusted for age using the distribution of the Finnish population aged $\geqslant 30 \mathrm{yrs}$ in 1980 . Otherwise, the survey data were compared using multivariable logistic models, including age as one of the determinants. First-order interactions between the covariates were tested, and the interaction terms were included in the models whenever statistically significant. Relative ORs with 95\% CIs were calculated to evaluate the independent roles of the potential determinants of COPD in the two surveys.

\section{RESULTS}

Table 1 describes the distributions of basic characteristics in the study populations. The sex and age distributions were similar. The mean values of height and weight, and the level of education and reported leisure physical activity were slightly higher in both males and females in the Health 2000 Survey. In the Health 2000 Survey, the proportions of current and former smokers were smaller, and the proportion of never-smokers was larger among males. In contrast, among females, the proportion of never-smokers was smaller, and the proportions of current and former smokers were larger. In both males and females, the prevalence of previously diagnosed asthma was higher in the Health 2000 Survey, whereas previously diagnosed pulmonary tuberculosis was reported by $1.0 \%$ of males and $0.4 \%$ of females in the Mini-Finland Health Survey but by none in the Health 2000 Survey.
The spirometric results (FEV1, FEV1 \% pred, FVC, FVC \% pred and FEV1/FVC) were similar in the two surveys (table 2), even though, as expected, most of the mean values differed significantly from each other owing to the large number of observations.

Figure 1 shows the prevalence of obstruction (FEV1/FVC $<$ LLN) according to age group in males and females 3074 yrs of age in the two surveys. The prevalence was higher in males in all age groups in both surveys, with the exception of the youngest age group (30-44 yrs) in 2000-2001. When adjusted for age, the prevalence for males was $4.7 \%$ in 1978 1980 , and $4.3 \%$ in $2000-2001$. The corresponding figures for females were 2.2 and $3.1 \%$, respectively. In males, the prevalence was lower in the Health 2000 Survey in those aged 45-54 yrs and 55-64 yrs, but it was somewhat higher in the age groups $30-44$ yrs and 65-74 yrs. For females, however, the prevalence in the later survey tended to be higher across all age groups, with the exception of those aged 55-64 yrs.

Table 3 shows how the age-adjusted prevalence of obstruction varied in males and females according to the stages of COPD in the two surveys. Data is provided for each of the four stages, for a combination of stages I-IV and II-IV, and for stages II-IV excluding participants with previously diagnosed asthma.

Little difference was found between the two surveys in any of the age-adjusted prevalence rates for COPD stages II-IV in either sex. However, in females the rate of stage I was significantly higher in the later survey $(p=0.001)$, even when further adjusted for smoking $(p=0.01)$. In addition, for stages I-IV combined, the age-adjusted prevalence was almost significantly

TABLE 3 Prevalence of bronchial obstruction according to chronic obstructive pulmonary disease (COPD) stages in the two surveys

\begin{tabular}{|c|c|c|c|c|}
\hline & \multirow[t]{2}{*}{ Mini-Finland Health Survey } & \multirow[t]{2}{*}{ Health 2000 Survey } & \multicolumn{2}{|c|}{$p$-values } \\
\hline & & & Adjusted for age & $\begin{array}{l}\text { Adjusted for age } \\
\text { and smoking }\end{array}$ \\
\hline Males $\mathbf{n}$ & 3015 & 2572 & & \\
\hline Stage I & 0.8 & 0.6 & 0.62 & 0.54 \\
\hline Stage IV & 0.4 & 0.4 & 0.91 & $0.92^{*}$ \\
\hline Stage I-IV & 4.7 & 4.3 & 0.25 & $0.69^{\circ}$ \\
\hline Stage II-IV & 3.9 & 3.6 & 0.36 & $0.94^{\circ}$ \\
\hline Stage II-IV\# & 3.5 & 2.9 & 0.11 & $0.42^{\circ}$ \\
\hline Females $n$ & 3349 & 2923 & & \\
\hline Stage I & 0.8 & 1.5 & 0.001 & 0.01 \\
\hline Stage I-IV & 2.2 & 3.1 & 0.06 & 0.44 \\
\hline Stage II-IV & 1.4 & 1.5 & 0.93 & 0.46 \\
\hline Stage $\|-I V^{\#}$ & 1.2 & 1.0 & 0.47 & 0.16 \\
\hline
\end{tabular}

Data are presented as \%, unless otherwise stated. ${ }^{*}$ : asthmatic subjects excluded; ${ }^{\bullet}$ : significant interaction between age and smoking, interaction term included in the mode 
higher in females in the later survey compared with the earlier survey $(p=0.06)$. Otherwise, no significant differences were found between the surveys in either sex (table 3).

Excluding subjects with an abnormal nonspecific pattern of pulmonary function test (279 males and 215 females in the earlier survey, and 355 males and 296 females in the later survey) and adjusting the analysis for age and smoking, in a similar way to table 3 , no significant differences were found in the prevalence rates of obstruction (COPD stages I-IV) between the two surveys ( $p=0.92$ males; $p=0.31$ females).

In multivariable logistic models, age group, low body mass index (BMI), low level of education, low or moderate physical activity, former or current smoking, previously diagnosed asthma, and previously diagnosed pulmonary tuberculosis were found to be independent determinants of COPD stages IIV in the survey conducted in 1978-1980. In 2000-2001, the results were remarkably similar, with the exception of both the level of education and the level of physical activity, which showed no significant association with COPD (table 4). The risk of COPD was particularly strongly associated with age, current smoking and previous asthma. In the earlier survey, a strong association was also found for past tuberculosis.

Table 5 shows corresponding results for COPD according to a stricter definition (stages II-IV, excluding asthmatic subjects). The results resembled those presented in table 4, although the risk of COPD was significantly associated with male sex and clearly more strongly associated with age group and current smoking, especially in the later survey.

\section{DISCUSSION}

We analysed the prevalence rates of airway obstruction (fig. 1) and various stages of COPD (table 3 ) among subjects aged

TABLE 4 Potential determinants of chronic obstructive pulmonary disease (COPD) stages I-IV in the two surveys

Determinants

\section{Age group yrs}

30-44

45-54

55-64

65-74

Sex

Females

Males

BMI $\mathbf{k g} \cdot \mathbf{m}^{-2}$

$<25$

25-29.9

$\geqslant 30$

Level of education

Higher

Secondary

Basic

Physical activity at leisure

High

Moderate

Low

Smoking status

Never

Former

Current

Previously diagnosed asthma

No

Yes

Previously diagnosed pulmonary TB

No

Yes
Health Survey in 1978-1980

\begin{tabular}{ll}
\hline Subjects n & $\begin{array}{l}\text { Subjects with } \\
\text { COPD stages } \\
\text { I-IV n }\end{array}$
\end{tabular}

Health Survey in 2000-2001

Subjects $\mathbf{n}$

\section{Subjects with}

COPD stages

I-IV n
OR $(95 \% \mathrm{Cl})$

\begin{tabular}{|c|c|c|c|c|c|}
\hline 2618 & 47 & 1 & 2089 & 54 & 1 \\
\hline 1546 & 43 & $1.49(1.02-2.19)$ & 1583 & 39 & $1.01(0.66-1.56)$ \\
\hline 1252 & 57 & $2.42(1.50-3.91)$ & 1065 & 40 & 2.07 (1.28-3.33) \\
\hline 948 & 64 & $4.28(2.74-6.68)$ & 758 & 59 & $4.84(3.05-7.70)$ \\
\hline 3349 & 75 & 1 & 2923 & 89 & 1 \\
\hline 3015 & 136 & $1.32(0.91-1.93)$ & 2572 & 103 & $1.11(0.79-1.56)$ \\
\hline 2905 & 121 & 1 & 2071 & 96 & 1 \\
\hline 2508 & 67 & $0.52(0.38-0.72)$ & 2209 & 65 & $0.51(0.35-0.74)$ \\
\hline 951 & 23 & $0.44(0.28-0.71)$ & 1214 & 31 & $0.39(0.25-0.61)$ \\
\hline 767 & 8 & 1 & 1691 & 44 & 1 \\
\hline 1408 & 27 & $1.51(0.62-3.69)$ & 1868 & 46 & $0.75(0.49-1.16)$ \\
\hline 4174 & 174 & $2.73(1.21-6.18)$ & 1916 & 99 & $1.19(0.81-1.75)$ \\
\hline 1041 & 14 & 1 & 1020 & 36 & 1 \\
\hline 3178 & 91 & $1.97(1.00-3.85)$ & 3051 & 97 & $0.78(0.49-1.22)$ \\
\hline 2143 & 106 & $2.88(1.43-5.81)$ & 1344 & 52 & $0.94(0.58-1.52)$ \\
\hline 3403 & 57 & 1 & 2719 & 41 & 1 \\
\hline 1374 & 53 & $2.24(1.41-3.56)$ & 1178 & 51 & $3.02(1.98-4.60)$ \\
\hline \multirow[t]{2}{*}{1582} & 101 & $4.11(2.81-6.02)$ & 1578 & 97 & $6.14(3.94-9.58)$ \\
\hline & & & & & 1 \\
\hline 6250 & 186 & 1 & 5273 & 155 & \\
\hline 114 & 25 & $11.77(7.43-18.65)$ & 222 & 37 & $6.73(4.30-10.53)$ \\
\hline 6317 & 199 & 1 & & & \\
\hline 47 & 12 & $7.23(3.40-15.36)$ & & & \\
\hline
\end{tabular}

Diagnosis of pulmonary tuberculosis (TB) was not analysed in subjects in the Health 200 Survey due to insufficient data. Multivariates were adjusted for all covariates

listed in this table. BMl: body mass index. 


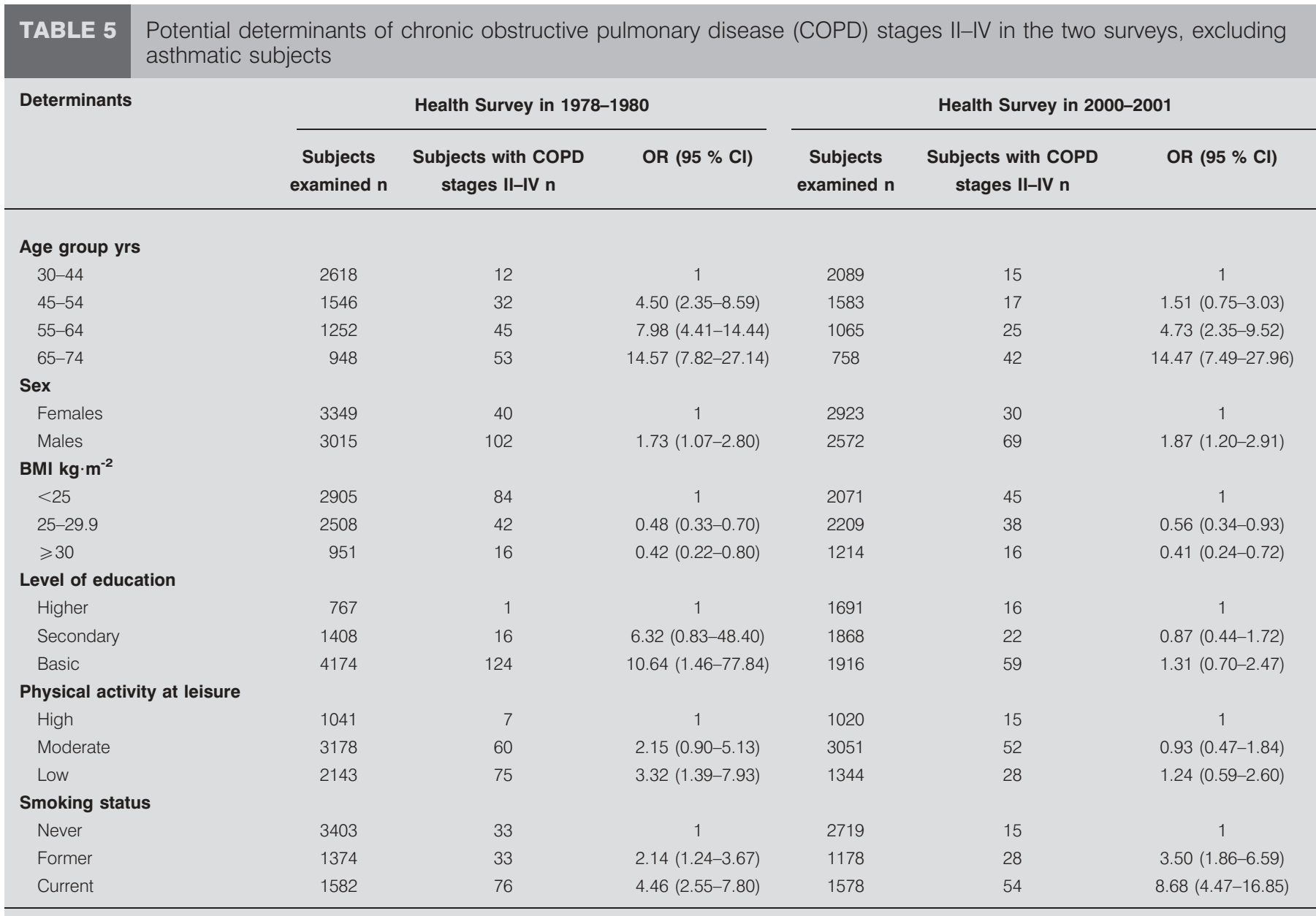

Previously diagnosed pulmonary tuberculosis was not analysed due to an insufficient number of cases. Multivariates were adjusted for all covariates listed in this table. BMI: body mass index.

30-74 yrs in two population surveys conducted in Finland 20 yrs apart. For males, the prevalence of COPD (stages II-IV), excluding those with previously diagnosed asthma, was $3.5 \%$ in 1978-1980, and $2.9 \%$ in 2000-2001. For females, the corresponding figures were $1.2 \%$ in the earlier survey and $1.0 \%$ in the later (table 3 ).

The samples were representative of the Finnish adult population and the participation rates were exceptionally high for comprehensive surveys like these. Moreover, essentially the same questions were asked about tobacco smoking and previous illnesses diagnosed by a physician (including asthma) in the two surveys. The same type of device from the same manufacturer was used for spirometry, which was performed according to the same guidelines. The results from the two surveys can therefore be confidently compared and generalised to the adult Finnish population. The comparability was further enhanced by SUDAAN weighting adjustments, allowing for non-participation and sample stratification. Age adjustments were made using weights from the 1980 population in order to obtain directly comparable results.

Of course, the two surveys could not be identical in all respects. In the Mini Finland Health Survey, the field work was carried out in two phases (a screening phase and a clinical examination phase) during a period of $>2$ yrs by only one team [12]. In the Health 2000 Survey, there were five field units, and each study locality was visited only once [14].

The prevalence of airway obstruction and various stages of COPD proved to be similar among both males and females in the two surveys, in spite of the 20-yr gap between them. In both surveys, the age-adjusted prevalence rates of COPD stages II-IV were clearly higher in males. Such findings could be expected on the basis of known differences in smoking habits between males and females. However, this difference between the sexes seems to be diminishing (table 3). These findings conform to differences in smoking status between the surveys (table 1) and the risk factor trends in Finland. The prevalence of smoking has shown a substantial decline among males, from the top level of $\sim 50 \%$ in some areas in the 1970 s, to the general level of just above $30 \%$ in 1997, and an increase from $\sim 10$ to $20 \%$ among females between the 1970 s and 2002 [20]. From 1982 to 1997, the decline in the prevalence of smoking among males was particularly marked in those aged 55-64 yrs (from $\sim 37$ to $23 \%$ ), whereas in females there was increase in all studied age groups [21]. A weakness of our study was that we didn't collect information on smoking as 
pack-yrs for those who were former smokers; we were therefore unable to use this parameter.

Past pulmonary tuberculosis was reported by $1.0 \%$ of males and $0.4 \%$ of females in the Mini Finland Health Survey, but was not reported by any of the subjects in the Health 2000 Survey. Pulmonary tuberculosis can result in bronchial obstruction that is indistinguishable from COPD $[22,23]$. Such sequelae must have become less frequent along with the markedly reduced incidence of tuberculosis in Finland since the 1950s [24, 25].

When adjusted for age and smoking, the prevalence rates of obstruction (stages I-IV) showed no significant differences between the two surveys, regardless of whether the subjects with an abnormal nonspecific pattern of pulmonary function test were included in the analysis. Thus, the rates of obstruction were not interconnected with parallel rates of such an abnormal pattern of pulmonary function in the surveys. The independent determinants of COPD proved to be remarkably similar in the two surveys (tables 4 and 5).

Earlier studies on the prevalence of COPD [11, 26-28] and its trends over the course of time $[29,30]$ have been confined to certain communities or areas within a country. Few studies have been based on wider representative study populations [31, 32], but even then only one single study has been carried out. Owing in the main to the differences in the age structures of the study populations, our overall (age-adjusted) findings concerning, for example, the rates of stage II-IV COPD (table 3), are substantially lower than those in the Burden of Lung Disease (BOLD) study $(9.1 \%$ in males and $7.6 \%$ in females) using a comparable criterion, FEV1/FVC $<$ LLN and FEV1 $<80 \%$ pred [10]. Our study was confined to those aged 30-74 yrs, whereas the BOLD study covered subjects who were $\geqslant 40$ yrs of age. Even in our study, the findings on obstruction and COPD showed a strong positive correlation with age (fig. 1, and tables 4 and 5). The mean prevalence of obstruction ranged between the youngest age group (30-44 yrs) and the oldest (65-74 yrs) from 1.5 to 12.1 for males in the earlier survey and from 1.7 to 13.4 in the later survey; the corresponding ranges were 2.1 to 2.9 and from 3.4 to 3.5 (fig. 1) in females.

Special attention was paid to the quality of all measurements in our health surveys $[11,13]$. The technicians were specially trained to perform spirometry according to the internationally recommended guidelines. Only tests adhering to the procedural guidelines were accepted. The same type of bellow spirometer from the same manufacturer was used for all measurements in the surveys. Nevertheless, we cannot be certain that the measurement results from the two surveys were definitely comparable because cross-calibrations between the devices could not be made. Even the personnel and the working conditions are inevitably subject to change over the decades. However, it is worth pointing out that the mean values of the measurements were remarkably similar in the two surveys (table 2). Besides, airway obstruction is not defined on the basis of the measured values as such but computed as the quotient of FEV1/FVC compared with the corresponding value from an appropriate reference population. In addition, classification into the four stages of COPD was based on comparisons between the recorded FEV1 values and those predicted. The same Swiss Study on Air Pollution and Lung Disease In Adults (SAPALDIA) reference values [17] were used in both of our surveys. To conform to the age structure of the reference values, we confined our analysis to subjects $<75$ yrs of age.

We conclude that when adjusted for age, the prevalence of airway obstruction (stages I-IV combined) showed no change among males and only a slight, statistically insignificant increase among females during two decades in Finland. These findings conform well to the trends seen in smoking among males and females since the early 1970s and towards the end of the century in Finland. Moreover, contrary to expectations, no significant difference was found in the prevalence of COPD stages II-IV in either sex. It should be emphasised that these results are not directly applicable to other countries. Nevertheless, our results suggest that the prevalence of COPD can be expected to vary along with changes in the factors predisposing to obstruction. In our study, COPD was predominantly mild or moderate. Since smoking cessation at an early stage usually stops progression of this disease, there is a strong case for early prevention.

\section{STATEMENT OF INTEREST}

A statement of interest for S. Saarelainen can be found at www.erj. ersjournals.com $/ \mathrm{misc} /$ statements.dtl

\section{REFERENCES}

1 Anto JM, Vermeire P, Vestbo J, et al. Epidemiology of chronic obstructive pulmonary disease. Eur Respir J 2001; 17: 982-994.

2 Pauwels RA, Rabe KF. Burden and clinical features of chronic obstructive pulmonary disease (COPD). Lancet 2004; 364: 613-620.

3 Lopez AD, Shibuya K, Rao C, et al. Chronic obstructive pulmonary disease: current burden and future projections. Eur Respir J 2006; 27: 397-412.

4 Davis RM, Novotny TE. The epidemiology of cigarette smoking and its impact on chronic obstructive pulmonary disease. Am Rev Respir Dis 1989; 140: S82-S84.

5 Global Initiative for Chronic Obstructive Lung Disease. Global strategy for the diagnosis, management, and prevention of chronic obstructive pulmonary disease. http://www.goldcopd.com/ Guidelineitem.asp?11 $=2 \& 12=1 \&$ intId $=2003$ Date last updated: December 2009. Date last accessed: April 2009.

6 Miller MR, Pedersen OF, Pellegrino R, et al. Debating the definition of airflow obstruction: time to move on? Eur Respir J 2009; 34: 527-528.

7 Hansen JE, Sun XG, Wasserman K. Spirometric criteria for airway obstruction: use percentage of FEV1/FVC ratio below the fifth percentile, not 70\%. Chest 2007; 131: 349-355.

8 Swanney MP, Ruppel G, Enright PL, et al. Using the lower limit of normal for the FEV1/FVC ratio reduces the misclassification of airway obstruction. Thorax 2008; 63: 1046-1051.

9 Cerveri I, Corsico AG, Accordini S, et al. Underestimation of airflow obstruction among young adults using FEV1/FVC, 70\% as a fixed cut-off: a longitudinal evaluation of clinical and functional outcomes. Thorax 2008; 63: 1040-1045.

10 Vollmer WM, Gislason Th, Burney $\mathrm{P}$, et al. Comparison of spirometry criteria for the diagnosis of COPD: results from the BOLD study. Eur Respir J 2009; 34: 588-597.

11 Buist AS, McBurnie MA, Vollmer WM, et al. International variation in the prevalence of COPD (the BOLD Study): a population-based prevalence study. Lancet 2007; 370: 741-750.

12 Aromaa A, Heliövaara M, Impivaara O, et al. Terveys, toimintakyky ja hoidontarve Suomessa [in Finnish with English summary]. Helsinki, Publications of the National Public Health Institute AL, 1989. 
13 von Hertzen L, Reunanen A, Impivaara O, et al. Airway obstruction in relation to symptoms in chronic respiratory disease - a nationally representative population study. Respir Med 2000; 94: 356-363.

14 Heistaro S, ed. Methodology Report. Health 2000 Survey. Publications of the National Public Health Institute B 26/2008. Helsinki, National Public Health Institute, 2008.

15 Aromaa A, Koskinen S, eds. Health and Functional Capacity in Finland. Baseline Results of the Health 2000 Health Examination Survey. Publications of the National Public Health Institute B12/ 2004. Helsinki, National Public Health Institute, 2004.

16 Pellegrino RC, Viegi G, Brusasco V, et al. Interpretive strategies for lung function tests. Eur Respir J 2005; 26: 948-968.

17 Brändli $\mathrm{O}$, Schindler $\mathrm{Ch}$, Künzli $\mathrm{N}$, et al. Lung function in healthy never smoking adults: reference values and lower limits of normal of a Swiss population. Thorax 1996; 51: 277-283.

18 Hyatt R, Cowl C, Bjoraker J, et al. Conditions associated with an abnormal nonspecific pattern of pulmonary function tests. Chest 2009; 135: 419-424.

19 SUDAAN Language Manual, Release 9.0. Research Triangle Park, Research Triangle Institute, 2004.

20 Vartiainen E, Laatikainen T, Peltonen M, et al. Thirty-five-year trends in cardiovascular risk factors in Finland. Int $J$ Epidemiol 2010; 39: 504-418.

21 Laatikainen $\mathrm{T}$, Critchley J, Vartiainen E, et al. Explaining the decline in coronary heart disease mortality in Finland between 1982 and 1997. Am J Epidemiol 2005; 162: 764-773.

22 Hnizdo E, Singh T, Churchyard G. Chronic pulmonary function impairment caused by initial and recurrent pulmonary tuberculosis following treatment. Thorax 2000; 55: 32-38.
23 Chakrabarti B, Calverley PMA, Davies PDO. Tuberculosis and its incidence, special nature, and relationship with chronic obstructive pulmonary disease. Int J COPD 2007; 2: 263-272.

24 Härö AS. Cohort approach in tuberculosis surveillance: comparison of the situation in Sweden and Finland. Tuber Lung Dis 1994; 75: 271-282.

25 Tala-Heikkilä M. Tuberculosis in Finland [article in Finnish] Duodecim 2003; 119: 1621-1628.

26 Murtaugh E, Heaney L, Gingles J, et al. The prevalence of obstructive lung disease in a general population sample: The NICECOPD study. Eur J Epidemiol 2005; 20: 443-453.

27 Hedman J, Kaprio J, Poussa T, et al. Prevalence of asthma, aspirin intolerance, nasal polyposis and chronic obstructive pulmonary disease in a population-based study. Int J Epidemiol 1999; 28: 717-722.

28 Kotaniemi J, Sovijärvi A, Lundbäck B. Chronic obstructive pulmonary disease in Finland: prevalence and risk factors. COPD 2005; 2: 331-339.

29 Lindström $\mathrm{M}$, Jönsson $\mathrm{E}$, Larsson $\mathrm{K}$, et al. Underdiagnosis of chronic obstructive pulmonary disease in Northern Sweden. Int $J$ Tuberc Lung Dis 2001; 6: 76-84.

30 Johannessen A, Omenaas E, Bakke P, et al. Incidence of GOLDdefined chronic obstructive pulmonary disease in a general adult population. Int J Tuberc Lung Dis 2005; 9: 926-932.

31 Tzanakis N, Anagnostopoulou U, Filaditaki V, et al. Prevalence of COPD in Greece. Chest 2004; 125: 892-900.

32 Shahab L, Jarvis M, Britton J, et al. Prevalence, diagnosis and relation to tobacco dependence of chronic obstructive pulmonary disease in a nationally representative population sample. Thorax 2006; 61: 1043-1047. 